\title{
BOCHKOVOCOPTIDAE, AN UNUSUAL NEW FAMILY OF PSOROPTIDIAN MITES (ACARI: ASTIGMATA) ASSOCIATED WITH OTOMYS DENTI (RODENTIA: MURIDAE) FROM UGANDA
}

\section{Barry M. OConnor}

\author{
Department of Ecology and Evolutionary Biology, Museum of Zoology, University of Michigan, \\ Ann Arbor, Michigan, USA \\ e-mail: bmoc@umich.edu
}

\begin{abstract}
A new family, Bochkovocoptidae, is proposed for a new genus and species of psoroptidian mite (Astigmata), Bochkovocoptes otomys sp. n., collected from the follicles of the facial vibrissae of Otomys denti (Rodentia: Muridae) from Uganda. The new taxon is characterized by retrorse processes and striated apical membranes on the subcapitular rutella, strong retrorse processes on the segments of the anterior legs, well developed pretarsi on legs I-III and a reduced pretarsus on leg IV. The new taxon is hypothesized to be related to the families Sarcoptidae and Rhyncoptidae.
\end{abstract}

KEY WORDS: Follicle parasite, taxonomy, Africa.

DOI: 10.21684/0132-8077-2019-27-2-145-150

\section{INTRODUCTION}

During the examination of a collection of small mammals collected in Uganda by Dr. Julian Kerbis Peterhans of the Field Museum of Natural History, Chicago, USA (FMNH), I collected a small series of mites from the follicles of the facial vibrissae of a fluid-preserved specimen of Dent's Vlei Rat, Otomys denti Thomas, 1906. This host and the related Otomys lacustris G.M. Allen and Loveridge, 1933, occupy montane habitats in the so-called east African 'montane circle' (the chain of mountain ranges associated with the African Rift et Eastern Arc archipelago) (Taylor et al. 2009).

The mites belong to the largely parasitic lineage of Astigmata named Psoroptidia (OConnor 2009). The only existing psoroptidian family that includes mites which inhabit the follicles of the vibrissae of mammalian hosts is Rhyncoptidae (Klompen 1993). However, the new species lacks retrorse processes on the palps and retains a pretarsus on leg IV (rhyncoptid mites bear palpal processes and lack pretarsus IV), so Bochkovocoptes cannot be easily accommodated in this family. The combination of morphological characters exhibited by the new species precludes the inclusion in any other existing mammal-associated psoroptidian families as diagnosed by OConnor (2009), Bochkov (2010) and Bochkov and Mironov (2011). The purpose of this paper is to describe this new mite and consider its morphology and systematic placement. Because only female specimens were collected, morphological characters of males or immature stages could not be considered, nor could patterns of ontogenetic transformations (Klompen and OConnor 1989).

\section{MATERIALS AND METHODS}

Host specimens were collected individually in the field, wrapped in cheesecloth to retain ectoparasites and minimize contamination, and fixed in formalin. In the museum, specimens were rinsed in water and then permanently stored in $70 \%$ ethanol. In the author's laboratory, host specimens were examined under a dissecting microscope and mites were individually collected into $70 \%$ ethanol. Mite specimens were cleared in lactophenol and mounted in Hoyer's medium. Specimens were examined with a Leica DMLB compound microscope with phase and differential interference contrast optics. Illustrations were made using a camera lucida. In the following descriptions, chaetotaxy for the body and legs follows OConnor (2009). All measurements are given in micrometers $(\mu \mathrm{m})$.

\section{SYSTEMATICS}

Superfamily Sarcoptoidea Murray, 1877 (sensu

Bochkov et Mironov 2011)

Family Bochkovocoptidae fam. n.

Type genus: Bochkovocoptes gen. n.

Diagnosis. Female. Cheliceral hood and ventral apophysis of movable digit not observed. Subcapitular rutella with striated apical membranes. Apices of palps without retrorse processes. Palps with both dorsal setae present, ventral seta absent. Idiosoma cylindrical. Supracoxal sclerite present, setae $s c x$ and supracoxal gland opening not observed. Ovipore in shape of an inverted Y. Epigynal apodeme well developed, fused with coxal apodemes II. Two pairs of genital papillae present, vestigial. Copulatory opening posterior dorsal, spermathecal duct thin. Anus terminal. 
Coxal field II with a strong retrorse process. Prodorsal sclerite large, remaining idiosoma unsclerotized, cuticle with coarse striations. All idiosomal setae filiform. Opisthosomal setae $h 3$ and $p 2$ absent. Pretarsi I-IV present, ambulacral disc absent on pretarsus IV; ambulacral sclerites present in disc. All leg segments free. Legs I-II with ventral processes on all segments except tarsi. Legs III-IV cylindrical, without processes. Setae $f t$ " of tarsi III-IV greatly elongated. All leg setae filiform except $t c$ " a short spine. Solenidia absent from legs III-IV. Seta v' present on trochanter IV.

Differential diagnosis. Bochkovocoptidae may be differentiated from the related family Rhyncoptidae by the possession of striated membranes on the subcapitular rutella, absence of retrorse processes on the palps, and presence of a pretarsus on leg IV. It may be differentiated from the family Sarcoptidae by the anterior-posterior elongation of the body, retention of paraproctal setae $p 3$ and the ovipore in the form of an inverted $\mathrm{V}$.

\section{Genus Bochkovocoptes gen. $\mathrm{n}$.}

Type species: Bochkovocoptes otomys sp.n.

Diagnosis. Female. Chelicerae robust, chelatedentate. Cheliceral hood and ventral apophysis of movable digit not observed. Palps two-segmented, with two dorsal setae and ventro-apical solenidion, setae l" absent, without retrorse processes apically. Rutella with lateral teeth and finely ridged apicoventral membranes. Subcapitulum with a pair of broad, ventral, retrorse processes. Ventral subcapitular setae and palpal supracoxal setae present.

Idiosoma somewhat elongated, cylindrical. Propodosomal sclerite well developed, bearing setae ro, scapular setae (in, ex) on each side positioned together on a small sclerite. Supracoxal sclerites thin, supracoxal gland openings and supracoxal setae not observed. Remainder of body unsclerotized. Dorsum with pattern of coarse striations and ridges. Idiosomal setal complement complete except lamellar (or external vertical) setae (le) and $h 3$ and $p 2$ absent. All body setae filiform. Opisthonotal gland openings (gla) anteromedial to setae $e 2$. Copulatory opening (co) dorsal, slightly anterior to level of setae $p l$.

Venter with coxal apodemes I fused to form sternum. Epigynal apodeme arched, fused laterally with anterior and posterior apodemes II. Apodemes III small, apodemes IV large, all ending freely. Coxal fields I, III and IV partially sclerotized. Coxal fields II with large, sclerotized spurs.
Ovipore in the form of an inverted Y. Genital valves striated; genital papillae vestigial, positioned under genital valves between setae $g$ and $4 b$. Ventral opisthosoma with pattern of coarse ridges becoming scale-like medially. Anus terminal. All ventral coxal and genital setae filiform.

Legs I-II strongly developed, all segments free, with ventral retrorse processes on trochanters, femora, genua and tibiae. Tarsi I and II very short and without apical or ventral processes. Legs III and IV cylindrical, without ventral processes on segments. Pretarsi I and II with well-developed ambulacral stalks and ambulacral discs. Ambulacral discs with small central hooked empodial remnant and paired lateral sclerites. Pretarsus III similar to pretarsi I and II but smaller; lateral sclerites of ambulacral disc not observed. Pretarsus IV consisting of only short ambulacral stalk, disc absent. All leg setae filiform except $t c$ " of tarsi I and II short strong spines. Trochanters I-IV with one filiform seta each. Femora I and II each with a filiform seta, seta of femur IV absent. Genua I and II with two filiform setae each, genu III without seta. Tibiae I-IV with one filiform seta each. Tarsi I and II with seven filiform setae and a short spine ( $t c$ "), tarsus III with four filiform setae, tarsus IV with five filiform setae ( $p v$ " absent on tarsus III, present on tarsus IV). Setae $f t$ " of tarsi III-IV extremely long, longer than the corresponding leg. Solenidia $\omega 1$ and $\omega 3$ apical on tarsus I. Solenidion $\omega 1$ apical on tarsus II, longer than corresponding structure on tarsus I. Solenidion $\varphi$ present on tibiae I and II, absent on tibiae III and IV. One solenidion $\sigma$ on genua I-II, none on genu III.

Etymology. The new taxon is named in honor of the late Andrei V. Bochkov in recognition of his extensive body of work on the systematics and phylogenetics of mites parasitic on vertebrates. The generic name is masculine.

\section{Bochkovocoptes otomys sp.n.}

(Figs. 1-2)

Type material. Holotype and three paratype females from follicles of facial vibrissae of Otomys denti kempi Dollman, 1915 (Rodentia: Muridae) (FMNH 157811), Uganda: Kigezi Province, Kisoro District, Mgahinga Gorilla National Park, edge of encroached area and park, along pipeline, lat/long: -1.3653, 29.65736, 13 March 1996, J.C. KerbisPeterhans (JCK 3280). Mites removed by B.M. OConnor (BMOC 96-1020-060).

Type depositories. Holotype and one paratype deposited in the Field Museum of Natural History, 


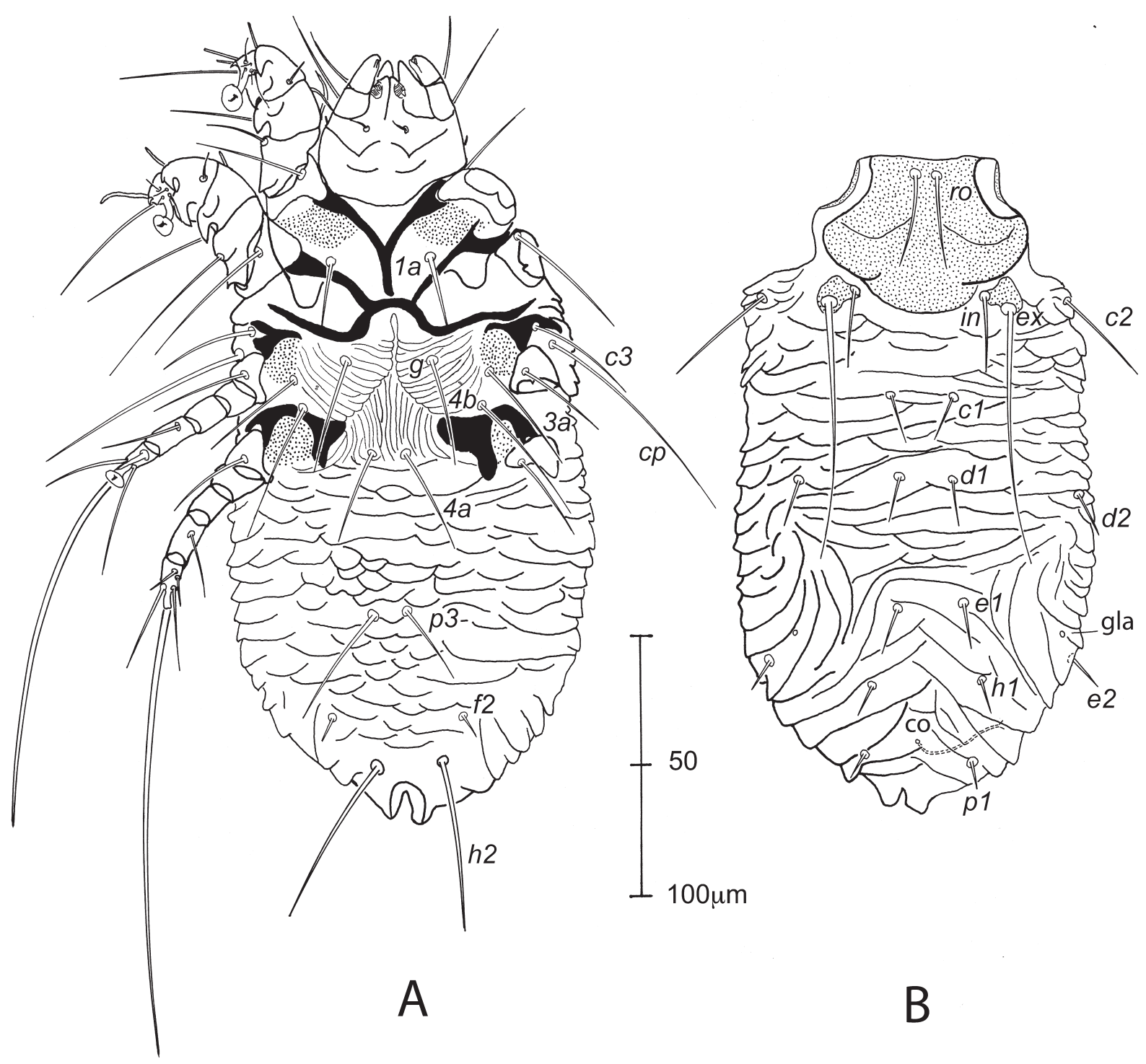

Fig. 1. Bochkovocoptes otomys, female. A-ventral view, B-dorsal view. Abbreviations: gla-opisthonotal gland opening, co-copulatory opening.

Chicago, Illinois, USA. One paratype each in the Museum of Zoology, University of Michigan, Ann Arbor, Michigan, USA, and the Zoological Institute, Russian Academy of Science, St. Petersburg, Russia.

Description. Female $(\mathrm{N}=4)$. Body (Fig. 1A, B), including gnathosoma, length 300-326, width 132-151. Gnathosoma broadly trapezoidal, length including palps 45-53, width 55-68. Chelicerae robust, chelate, length 55-60, fixed digit with two large teeth, movable digit with four smaller teeth. Palps 25-30 long, with two dorsal setae and short, subapical solenidion. Rutella (Fig. 2G) 15 long, with 2 lateral teeth.

Idiosoma. Propodosomal sclerite length 54-60, width 79-89, with paired posteriorly directed ridges at about mid-length. Propodosomal setae ro on sclerite, setae in and ex together on paired scler- ites. All idiosomal setae filiform, lengths: ro 32-44, in 22-29, ex 92-124, c1 17-19, c2 41-45, c3 41-44, cp 104-120, d1 15-18, d2:19-25, e1 15-16, e2 13-16,f2 8-11, h1 10-12, h2 59-64, pl 10-11, p3 $25-28$. Copulatory opening medial, slightly anterior to level of setae $p 1$. Spermathecal duct thin along length, spermathecal opening and ducts to ovaries not observed. Coxisternal apodemes as in family description. Setal lengths: $1 a$ 34-36, $3 a$ 50-53, 4a 30-37, 4b 48-58, g 44-48.

Legs (Fig. 2. A-F): Lengths from trochanter to tarsus: I 61-75, II 64-75, III 68-74, IV 70-75. Tarsal lengths: I 8-10, II 9-11, III 13-16, IV 12-13. Pretarsal lengths: I 16-20, II16-18, III 12, IV 8-10. Patterns of retrorse spurs and processes similar on legs I and II: trochanters with small ventrally directed process near base of seta $v$ ', femora with 


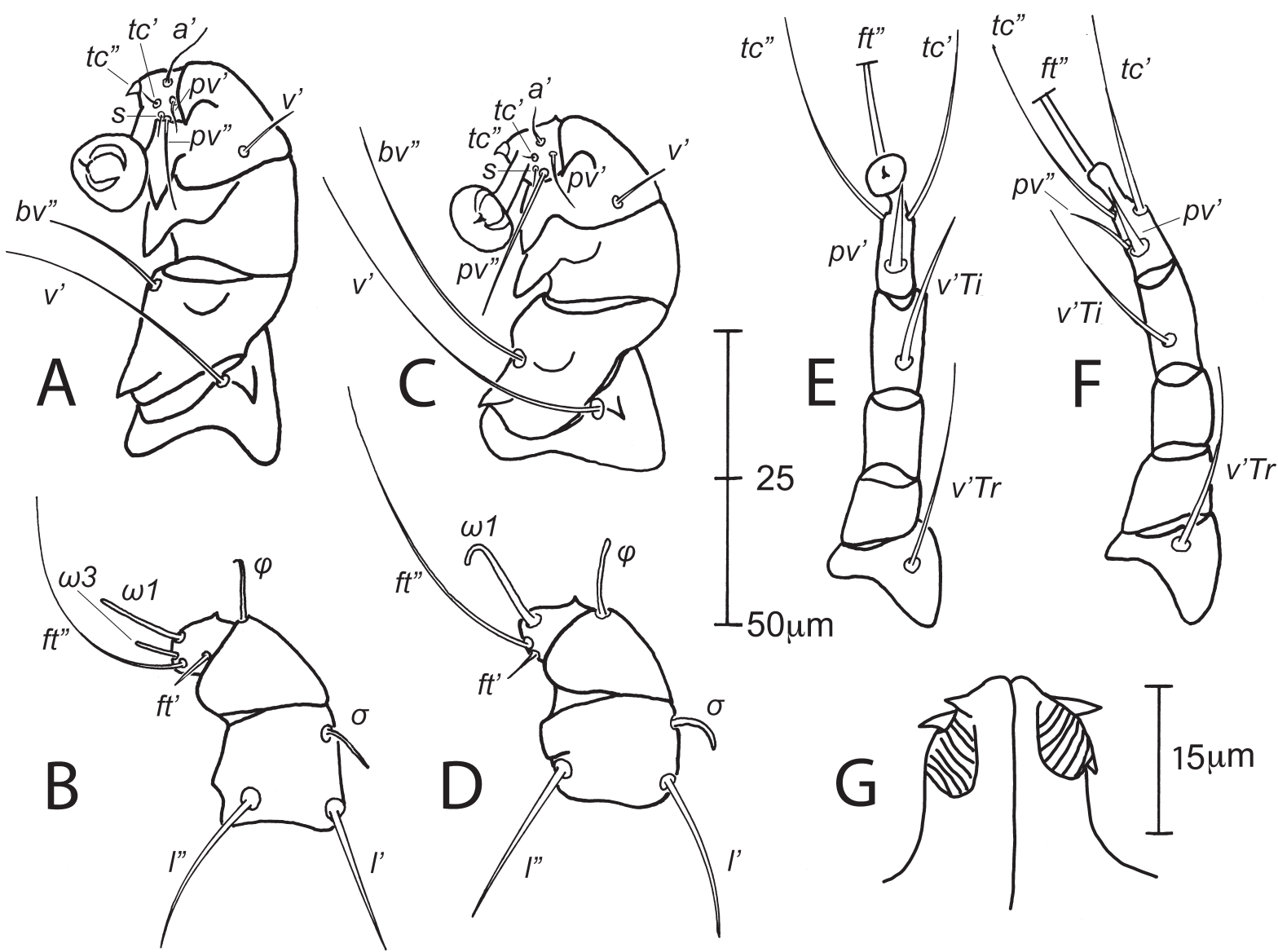

Fig. 2. Bochkovocoptes otomys, female. A-leg I ventral view, B-leg I dorsal view, C-leg II ventral view, D-leg II dorsal view, E-leg III ventral view, F-leg IV ventral view, G-subcapitular rutella. Scale bars: $50 \mu \mathrm{m}(\mathrm{A}-\mathrm{F}), 15 \mu \mathrm{m}(\mathrm{G})$.

pointed spur near base and rounded process more distal, genua with somewhat bilobed spur ventral in apical portion; tibiae with a pointed ventral spur and dorsoapical hooked process; tarsi with very small, pointed dorsal process near base. Setation of legs I and II similar but some setae of leg II longer than homologs on leg I; all setae filiform except $t c$ " a triangular spine. Solenidia of legs I and II: $\omega 1$ I 14-15, $\omega 3$ I 6-7, $\omega 1$ II 20 , hooked apically, $\varphi$ I 9-11, $\varphi$ II 10-13, $\sigma$ I 10-12, $\sigma$ II 8-10. Legs III and IV similar in form and setation, except $p v$ " absent on tarsus III. Solenidia absent from legs III and IV.

Etymology. The species name is a noun in apposition referring to the generic name of the host.

Remarks. Examination of three other specimens of Otomys denti from Tanzania, five specimens of $O$. tropicalis Thomas, 1902 from Tanzania and one from Rwanda, three specimens of $O$. anchietae Bocage, 1882 from Tanzania, three specimens of $O$. typus (Hueglin, 1877) from Uganda, one O. irroratus (Brants, 1827) from Uganda and one $O$. angoniensis Wroughton, 1906 from Malawi in the collections of the FMNH failed to yield any further specimens.

\section{DISCUSSION}

Homologies of posterior opisthosomal setae. Bochkov (2010) and Bochkov and Mironov (2011) have considered the presence or absence of certain notogastral and paraproctal setae as diagnostic for families and larger clades of psoroptidian mites. Thus, determining the homologies of the setae in these regions in Bochkovocoptes is critical. The setal complement in Bochkovocoptes is lacking two pairs of setae compared with the maximal complement of 15 pairs in most psoroptidian mites (Bochkov and Mironov 2011). Hypotheses of homology of setae across taxa can be informed by position or ontogeny (Klompen and OConnor 1989), the latter impossible for Bochkovocoptes, as their juvenile stages remain unknown. Positionally, it is clear that all setae of ancestral notogastral segments C, D and $\mathrm{E}$ are present in Bochkovocoptes. In their summary of idiosomal setal complements in mammalassociated Psoroptidia, Bochkov and Mironov (2011) indicate that seta $f 2$, the only seta present on segment $\mathrm{F}$ in Astigmata, is absent only in the endoparasitic families Lemurnyssidae and Pneu- 
mocoptidae (and some species of Gastronyssidae) and in the highly regressive mites of the family Chirorhynchobiidae, which lack most notogastral and paraproctal setae. Thus, I interpret the pair of very short setae ventro-mediad of setae $e 2$ as $f 2$. The seta that is positioned dorsally immediately posterior to seta $e_{1}$ could be interpreted as either hl or pl (psl of Bochkov and Mironov 2011). In larval Astigmata, segment $\mathrm{H}$ occupies the caudal bend and bears two pairs of setae, traditionally interpreted as $h 1$ and $h 2$. The families Psoroptidae and Lobalgidae have been interpreted as lacking seta $h l$ throughout ontogeny (Bochkov and Mironov 2011) because only one pair is present in the larva, with its position lateral to the anus marking it as $h 2$. With the addition of the setae of segment P (or PS) (and seta h3) in the protonymph, the $\mathrm{H}$ setae are shifted laterally and the $\mathrm{P}$ setae appear in the paraproctal position. In most postlarval stages of the mammal-associated Psoroptidia, the pair of long setae that typically occurs laterad of the anus has been interpreted as $h 2$. In taxa with a dorso-ventral flattening of the body (e.g., most Psoroptidae and bird associates), the $\mathrm{H}$ setae are typically shifted more laterally than in more elongate, rounded or cylindrical taxa (e.g., Rhyncoptidae). Thus, in Bochkovocoptes, I interpret the seta directly posterior to $e l$ as $h l$ and the longer pair laterad of the anus as $h 2$. The seta positioned dorsally behind $h l$ and laterad of the terminal anus is $p 1$. That leaves the ventral seta in the middle of the opisthosoma anterio-mediad of $f 2$, which I interpret as $p 3$ because in other taxa, $p 3$ is the most anterior of the paraproctal setae and is sometimes shifted far anteriad of the anus (e.g., some Gastronyssidae, Myocoptidae — see Bochkov 2010).

Systematic position of Bochkovocoptidae. Phylogenetic analyses by Klimov and OConnor (2008) (molecular data) and Bochkov and Mironov (2011) (morphological data) provided evidence that the association between psoroptidian mites and mammals evolved multiple times from earlier birdassociated psoroptidians. The results of the two studies were largely congruent in this regard, with Klimov and OConnor (2008) referring to the two lineages including mammal associates as belonging to the "Sarcoptid-Analgid" and "EpidermoptidPsoroptid" clades. Bochkov and Mironov (2011) recognized two superfamilies: Sarcoptoidea, including only mammal parasites, and Psoroptoidea, including both mammal and bird parasites. In the key to families presented by Bochkov (2010), Bochkovocoptes belongs to the "Sarcoptid complex" and runs to the final couplet separating Sarcoptidae and Rhyncoptidae. However, Bochkovocoptes possesses a combination of character states that do not allow easy accommodation in either family. Specifically, Bochkovocoptes shares with Sarcoptidae the absence of retrorse processes on the palps (presumably, a plesiomorphy). Sarcoptidae all lack setae $p 3$, which are present in Bochkovocoptes. All Rhyncoptidae are characterized by retrorse processes at the apex of the palp, loss of the pretarsi from legs III and IV (apomorphies not shared with Bochkovocoptes) and retention of setae $p 3$ (a plesiomorphy shared with Bochkovocoptes).

The habitat and general body shape of Bochkovocoptes is most similar to those of most Rhyncoptidae. Like Bochkovocoptes, rhyncoptid mites inhabit hair follicles and also possess well developed processes on the anterior legs for anchorage in the follicles of their hosts. Most rhyncoptid mites (except Rhyncoptes) bear some modified dorsal hysterosomal setae ("layered" or bifurcate with a thickened and a flagelliform part) - a trait shared with some Sarcoptidae. By contrast, all hysterosomal setae of Bochkovocoptes are simple. The "modified dorsal setae" was one trait suggesting a sister-group relationship between Sarcoptidae and Rhyncoptidae (Klompen 1993).

A number of other lineages of Psoroptidia are characterized by retrorse processes on the leg segments. The pattern of what legs and segments bear these structures varies with the group, as does the form and position of various processes. Taxa with such processes include the subfamilies Makialginae and Marsupialginae in the family Psoroptidae, the family Listropsoralgidae and the subfamily Lemuroecinae in the family Chirodiscidae - all associated with mammals, and some taxa in the families Epidermoptidae and Dermationidae associated with birds. The mosaic distribution of these structures suggests convergent evolution in different lineages, where the mites use their legs to attach to the skin or hair/feather follicles of their hosts.

Another unusual characteristic of Bochkovocoptes is the presence of the $v$ 'seta on trochanter IV. This seta is absent in most Astigmata, but appears in taxa in very disparate groups, for example, in most species in the insect-associated family Canestriniidae (all genera except Megacanestrinia Tragardh, Donnelafontia Lavoipierre and Saniothiana Haitlinger) (e.g., Lavoipierre 1958), some species of insect-associated Heterocoptidae (Erotylocoptes Fain, Gascaricoptes Haitlinger, Conchycoptes Haitlinger, Kamerucoptes Haitlinger) (e.g., 
Haitlinger 2009), as well as some bird-associated Laminosioptidae (Fainocoptinae) (e.g., Lukoschus and Lombert 1980), Epidermoptidae (Myialges, Archemyialges, some Metamicrolichus) (Fain, 1965) and Analgidae (Strelkoviacarus holoaspis) (Mironov et al. 2010).

Bochkovocoptes appears to be most similar to the families Sarcoptidae and Rhyncoptidae, although cannot be accommodated in either. Thus, the designation of a new family, Bochkovocoptidae, for this mite appears warranted.

\section{ACKNOWLEDGMENTS}

I thank Julian Kerbis Peterhans and the late William Stanley of the Field Museum of Natural History for allowing me to examine the mammal specimens collected during their field expeditions in East Africa. I am especially appreciative of the late Andrei Bochkov of the Zoological Institute, Russian Academy of Science, for stimulating discussions regarding the new mite and other parasitic Acari. Pavel Klimov provided suggestions on the manuscript. Portions of this study were funded by the US National Science Foundation (DEB-0118766) to Barry OConnor.

\section{REFERENCES}

Bochkov, A.V. 2010. A review of mammal-associated Psoroptidia (Acariformes: Astigmata). Acarina, 18: 99-260.

Bochkov, A.V. and Mironov, S.V. 2011. Phylogeny and systematics of mammal-associated psoroptidian mites (Acariformes:Astigmata: Psoroptidia) derived from external morphology. Invertebrate Systematics, 25: 22-59.

Fain, A. 1965. A review of the family Epidermoptidae Trouessart parasitic on the skin of birds. Koninklijke Vlaamse Academie voor Wetenschappen, Letteren en Schone Kunsten van Belgie, 84: 1-176 (Pt. I, text), 1-144 (Pt. II, illustrations).

Haitlinger, R. 2009. Nine new species and new records of mites (Acari: Astigmata: Heterocoptidae) from tropical Africa. Revista Iberica de Aracnología, 17: 97-115.

Klimov, P.B. and OConnor, B.M. 2008. Origin and higher-level relationships of psoroptidian mites (Acari: Astigmata: Psorptidia): evidence from three nuclear genes. Molecular Phylogenetics and Evolution, 47: 1135-1156.

Klompen, J.S.H. 1993. Phylogenetic relationships in the skin-inhabiting Sarcoptoidea (Acari: Astigmata). Systematic Parasitology, 24: 17-33.

Klompen, J.S.H. and OConnor, B.M. 1989. Ontogenetic patterns and phylogenetic analysis in Acari. In: H.M. Andre and J.-Cl. Lions (Eds.). The concept of stase and the ontogeny of arthropods. AGAR Publishers, Belgium, Wavre, pp. 91-103.

Lavoipierre, M.M.J. 1958. Notes Acarologiques I. Deux nouveaux genres et quatre nouvelles especes d'acariens (Acarina, Mesostigmata et Sarcoptiformes) de l'Afrique occidentale et orientale. Annales de Parasitologie Humaine et Comparee, 33: 603-618.

Lukoschus, F.S. and Lombert, H.A.P.M. 1980. Five new species of quill wall mites from European birds (Astigmata: Laminosioptidae: Fainocoptinae). International Journal of Acarology, 6: 63-78.

Mironov, S.V., Skirnisson, K., Thorarinsdottir, S. Th. and Nielsen, O.K. 2010. Feather mites (Astigmata: Psoroptidia) parasitising the rock ptarmigan Lagopus muta (Montin) (Aves: Galliformes) in Iceland. Systematic Parasitology, 75: 187-206.

OConnor, B.M. 2009. Cohort Astigmatina. In: G.W. Krantz and D.E. Walter (Eds.). A Manual of Acarology. $3^{\text {rd }}$ edition. Texas Tech University Press, Lubbock, pp. 565-657.

Taylor, P.J., Maree, S., van Sandwyk, J., Kerbis Peterhans, J.C., Stanley, W.T., Verheyen, E., Kaliba, P., Verheyen, W., Kaleme, P. and Bennett, N.C. 2009. Speciation mirrors geomorphology and palaeoclimatic history in African laminate-toothed rats (Muridae: Otomyini) of the Otomys denti and Otomys lacustris species-complexes in the 'Montane Circle' of East Africa. Biological Journal of the Linnean Society, 96: 913-941. 